\section{Anaphylactoid reactions following propofol-atracurium sequence}

\section{To the Editor:}

In a letter to the editor Mohamed Naguib states, the "combination of propofol and atracurium may be followed by frequent anaphylactoid reactions and bronchospasm." Although anaphylactoid reactions with this drug combination are possible, I believe Dr. Naguib has unfairly represented the frequency of this potential side effect. His observations, in my estimation, more likely represent a worst case scenario and result from potential clinical mismanagement.

To summarize the clinical technique utilized by $\mathrm{Dr}$. Naguib, thirteen ASA Class I patients undergoing elective surgical procedures had anaesthesia induced with propofol (2.5 $\mathrm{mg} \cdot \mathrm{kg}^{-1}$ ) administered IV over $15 \mathrm{sec}$ followed by atracurium $\left(0.5 \mathrm{mg} \cdot \mathrm{kg}^{-1}\right)$ administered IV over 5 seconds. The author observed erythema and wheals along the path of the injected vein in 11 patients $(85$ per cent) and bronchospasm in three (23 per cent).

Propofol's manufacturer recommends that propofol be administered IV in a dose of $2.0-2.5 \mathrm{mg} \cdot \mathrm{kg}^{-1}$, but at a rate of $40 \mathrm{mg} \cdot 10 \mathrm{sec}^{-1} .^{2}$ In a large clinical trial, when propofol was properly administered at the suggested speed of initiation, flushing and cutaneous manifestations at the injection site occurred, but only with an incidence of 1-3 per cent. Bronchospasm was not observed in clinical trials, but has been reported with an incidence of less than one per cent. Dr. Naguib's induction technique employed a dose of propofol at the upper end of the suggested range $\left(2.5 \mathrm{mg} \cdot \mathrm{kg}^{-1}\right)$. Had that dose been administered at the rate suggested by the manufacturer, for an average $70 \mathrm{~kg}$ patient (Dr. Naguib's patients ranged from 50 to $78 \mathrm{~kg}$ ), an approximate $175 \mathrm{mg}$ dose should have been administered over $50 \mathrm{sec}$, rather than the $15 \mathrm{sec}$ described.

Atracurium when employed to facilitate tracheal intubation is suggested by its manufacturer to be administered as an IV bolus in a dose of $0.4-0.5 \mathrm{mg} \cdot \mathrm{kg}^{-1}$. In controlled clinical studies of 875 patients, atracurium administered in this recommended dose range resulted in skin flush, hives, and wheezing in 8.7,0, and 0.3 per cent of patients, respectively. ${ }^{3}$ Hypotension requiring treatment occurred in only five of 875 patients. Although not formally articulated in the product insert, it is well known that cutaneous manifestations and hypotensive side effects associated with intravenous adminstration of atracurium relate to the speed of injection. For example, Scott et al. ${ }^{4}$ have demonstrated that atracurium in a dose of $0.6 \mathrm{mg}$. $\mathrm{kg}^{-1}$ administered over five seconds resulted in an approximate doubling of the plasma histamine concentration which was accompanied by hypotension. However, when the same dose was titrated over 75 seconds, no changes in plasma histamine concentration or cardiovascular variables were observed.

As Dr. Naguib suggests, many of the described side effects from administration of propofol and atracurium are assumed to relate to their stimulation of histamine release. Histamine release and associated anaphylactoid reactions are related to the speed of injection of these drugs. It may be true as Dr. Naguib suggests, that the co-administration of propofol and atracurium potentiate each other's effects and result in an exaggerated histamine release with the potential for an anaphylactoid reaction. However, to generalize about the frequency of this complication after administration of these drugs in combination by a technique peculiar to the clinical practice of a sole user and in a way different from that recommended by the manufacturers and in a way likely to cause complications seems unfair. Before we implicate these drugs in the production of unwanted side effects, at the very least, this drug combination deserves to be studied scientifically with measurement of histamine levels while the drugs are co-administered in the proper dose range and by a techniqe recommended by the manufacturers.

Charles H. McLeskey MD

Associate Professor and

Director of Academic Affairs

Department of Anesthesiology

University of Colorado

Health Sciences Center

\section{REFERENCES}

1 Naguib M. Anaphylactoid reactions following propofolatracurium sequence. Can J Anaesth 1989; 36: 358-9.

2 Product insert for diprivan.

3 Atracurium product insert.

4 Scolt RPF, Savarese JJ, Basta SJ, et al. Atracurium: clinical strategies for preventing histamine release and attenuating the haemodynamic response. $\mathrm{Br} \mathrm{J}$ Anaesth $1985 ; 57: 550-3$.

\section{REPLY}

We share Dr. McLeskey's concern regarding the increased incidence of anaphylactoid reactions if $I V$ drugs (especially those capable of releasing histamine) are administered as bolus doses over $5-15 \mathrm{sec}$. The focus of our report was to point out a potential danger following a propofol-alracurium sequence as described. At the time of the siudy propofol was still in the phase II trials and we were using the coded drug (ICI 35,868). The manufacturer's recommendations regarding the rate of injection appeared at a later stage. It was not our intention, however. to represent any dramatic scenario of drug interactions. 
TABLE $\mathrm{ED}_{50}$ and $E D_{95}$ values $\left(\mathrm{mg} \cdot \mathrm{kg}^{-1}\right)$ of propofol for different end points of anaesthesia

\begin{tabular}{llllll}
\hline & $\begin{array}{l}\text { loss of } \\
\text { eyelash response }\end{array}$ & & \multicolumn{2}{l}{$\begin{array}{l}\text { Loss of } \\
\text { verbal response }\end{array}$} \\
\cline { 2 - 3 } \cline { 5 - 6 } & $E D_{50}$ & $E D_{95}$ & & $E D_{50}$ & $E D_{95}$ \\
& $(95 \% C I)$ & $(95 \% C l)$ & & $(95 \% C l)$ & $(95 \% C I)$ \\
\hline $30 \mathrm{sec}$ & 1.72 & 3.27 & 1.42 & 2.67 \\
& $(1.44-2)$ & $(2.44-4.39)$ & $(1.19-1.7)$ & $(2.06-3.46)$ \\
$60 \mathrm{sec}$ & 1.44 & 2.74 & 1.17 & 2.19 \\
& $(1.2-1.73)$ & $(2.11-3.57)$ & $(0.94-1.44)$ & $(1.72-2.79)$ \\
$90 \mathrm{sec}$ & 1.23 & 2.42 & 1.16 & 2.18 \\
& $(1.04-1.55)$ & $(1.88-3.11)$ & $(0.94-1.44)$ & $(1.71-2.78)$ \\
\hline
\end{tabular}

The suggestion that we used propofol at the upper end of the suggested range $\left(2.5 \mathrm{mg} \cdot \mathrm{kg}^{-1}\right)$ is naive. Leslie and Crankshaw ${ }^{2}$ reported that the $E D_{95}$ for propofol for loss of consiousness (defined as loss of ability to grasp a light object) was 2.56 $\mathrm{mg} \cdot \mathrm{kg}^{-1}$ of the calculated lean tissue mass. In addition, our data in the Table (unpublished observations) showed that the potency of propofol (i.e., a specific ED value) should be interpreted in conjunction with the time and the end-point used for loss of consiousness.

Although Dr. McLeskey suggested that measurement of histamine levels should be carried out before implicating any drug in the production of unwanted side effects, Barnes et al. ${ }^{3}$ found a poor correlation between plasma histamine levels and the clinical manifestations observed following atracurium.

We strongly support Dr. McLeskey's suggestion that further investigations of the effects of propofol-atracurium combination are needed.

Mohamed Naguib MD MSc FFARCSI

College of Medicine

Department of Anaesthesia (4I)

P.O. Box 7805, Riyadh 11472

Saudi Arabia

\section{REFERENCES}

1 Naguib $M$. Anaphylactoid reactions following propofolatracurium sequence. Can J Anaesth 1989; 36: 358-9.

2 Leslie K, Crankshaw DP. Potency of propofol for loss of consciousness after a single dose. $\mathrm{Br} J$ Anaesth 1990; 64: 734-6.

\section{Low-dose intrathecal- meperidine for lower limb orthopaedic surgery}

To the Editor:

We would like to report the effectiveness of low-dose $(0.5$ $\mathrm{mg} \cdot \mathrm{kg}^{-1}$ body weight) spinal meperidine anaesthesia for orthopaedic surgery involving open reduction-internal fixaton of femoral neck fracture.
Earlier investigations have shown that intrathecal meperidine is a weak local anaesthetic agent, and can be used as a sole anaesthetic. ${ }^{1,2}$ In these studies the dosage used was $1 \mathrm{mg} \cdot \mathrm{kg}^{-1}$ or $100 \mathrm{mg}^{2}$ as a bolus by intrathecal administration. However, a high incidence of complications such as bradycardia, hypotension and respiratory depression was associated with doses of $100 \mathrm{mg}^{2}$. Thus, we studied the efficacy of spinal meperidine at a reduced dose of $0.5 \mathrm{mg} \cdot \mathrm{kg}^{-1}$.

The study comprised six patients with a mean age of $74.6 \mathrm{yr}$. These patients were ASA physical status II-IV with a history of medical diseases including hypertension, diabetes, Alzheimer's disease, angina and previous myocardial infarction. Pre-anaesthetic medication consisted of diazepam $5 \mathrm{mg}$ PO. Intraoperative monitoring included modified $V_{5}$ electrocardiography, blood pressure by radial artery cannulation or by automated blood pressure machine (Critikon Dynbamap); oesophageal temperature; respiratory rate; pulse oximetry (Nellcor) and arterial blood gas ardynes, and central venous pressure in three patients. The anaesthetic technique included the intrathecal injection of preservative-free meperidine $0.5 \mathrm{mg}$. $\mathrm{kg}^{-1}$ (five per cent aqueous solution). Spinal injection was given in the lateral decubitus position, with the affected side dependent and patients remained in that position until they were moved on to the operating room table. Sensory block was tested with pin prick and ice cubes; motor blockade was assessed as per modified Bromage Score.

The mean onset of analgesia was $12 \mathrm{~min}$, the mean duration was $6 \mathrm{hr} 40 \mathrm{~min}$; the level of analgesia was $\mathrm{T}_{8}-\mathrm{T}_{11}$; the degree of motor blockade was grade " 0 " $(n$ : 3 ) and grade $1(n: 3)$ at 15 min after the spinal injection, and grade " 0 " in all patients in the recovery room. The operative conditions were good in all the patients. Midazolam $0.5 \mathrm{mg}-2 \mathrm{mg}$ was used as supple mental sedation in four patients. The haemodynamic variables were stable in five patients. One patient had a 20 per cent decrease in mean blood pressure $15 \mathrm{~min}$ after the spinal injection, and this was treated with ephedrine $5 \mathrm{mg}$ IV. Respiratory variables were stable in all patients throughout the perioperative period. Two patients complained of pruritus in the recovery room. The frequency of untoward effects was tabulated and compared with those of an earlier study ${ }^{2}$ in the Table.

Meperidine is a phenylpiperidine derivative which has many physical characteristics, including molecular weight and pKa, similar to local anaesthetic agents. Five per cent meperidine in aqueous solution is hyperbaric. The high lipid solubility of meperidine is responsible for its early onset of good analgesia. Also, its high lipophilicity reduces its cephalad spread, thus reducing the incidence of untoward effects such as respiratory depression. The 